\title{
Graphene supported Co-Mo-P catalyst for efficient photocatalyzed hydrogen generation
}

\author{
Yueping Guo ${ }^{1,2}$ Gongxuan Lu ${ }^{*}, 1$
}

${ }^{1}$ State Key Laboratory for Oxo Synthesis and Selective Oxidation, Lanzhou Institute of Chemical Physics, Chinese Academy of Science, Lanzhou, Gansu 730000

${ }^{2}$ College of Chemistry and Chemical Engineering, Lanzhou University, Lanzhou, Gansu 730000

*Corresponding author. Tel.: +86 9314968178.

E-mail addresses: gxlu@lzb.ac.cn, (G. Lu).

\begin{abstract}
In this work, graphene(GP) supported Co-Mo-P catalysts for $\mathrm{H}_{2}$ generation were prepared via an in-situ synthesis strategy with the help of photogenerated electrons. The transmission electron microscopy images (TEM) of the catalysts indicated that the elements of Co, Mo and $\mathrm{P}$ were distributed in a relatively homogeneous manner in the catalysts. The Co-Mo-P/GP catalyst exhibited high photocatalytic activity for hydrogen generation sensitized by Eosin Y (EY) under visible light. The $\mathrm{Mo} /(\mathrm{Co}+\mathrm{Mo})$ molar ratio $\left(\chi_{\mathrm{Mo}}\right)$ was varied in the catalyst to study the effect of Mo doping on the catalytic efficiency. The highest rate of the $\mathrm{H}_{2}$ generation was found to be as high as $33.3 \mathrm{mmol} \cdot \mathrm{h}^{-1} \cdot \mathrm{gCo}^{-1}$ when the $\chi_{\text {Mo was }} 10 \%$. The apparent quantum efficiency (AQE) of the reaction over the Mo doped catalyst under $430 \mathrm{~nm}$ irradiation was $52.6 \%$, which was six times higher than that using the un-doped Co-P/GO catalyst.
\end{abstract}

Key words: Graphene; Supported Co-Mo-P catalyst; Photocatalytic; Hydrogen generation 


\section{Introduction}

Hydrogen energy is increasingly being considered as a clean and alternative energy source, which can potentially help solve the global environmental pollution and energy security problems. Utilizing solar energy to produce $\mathrm{H}_{2}$ by means of a photocatalytic water splitting reaction has attracted widespread attention and considerable research efforts [1-6]. Many photocatalysts, such as the precious metals Pt, Rh and Pd are highly effective in producing $\mathrm{H}_{2}$ [7-10]; however, the high cost and scarcity of these metals limit their use in commercial applications.

Thus, it is essential to develop inexpensive and readily available materials to replace precious metal catalysts for sustainable development of hydrogen generation methods. It has been reported that an amorphous cobalt-phosphate compound can be used for the solar energy-driven oxidation of water to $\mathrm{O}_{2}$ [11-14]. The authors believed that the phosphate species acted as the proton acceptor, which is important for the charge separation in photochemical water splitting. Furthermore, phosphorous metalloid atoms have been used as $\mathrm{Co}-\mathrm{P}$ and $\mathrm{Ni}-\mathrm{P}$ derivatives for superior catalytic activity as they have the ability to modify the surface electronic states of the catalysts and their catalytic performance [15-17]. Due to these properties, P based catalysts are widely used to catalyze the production of hydrogen with high efficiency [18-21].

König et al.[22] has reported that a well-known fluorescent stain Eosin Y (EY) can be used as a photosensitizer and a redox catalyst, the redox potential of the photoproduced $\mathrm{EY}^{-}$is $-0.8 \mathrm{~V}$, which can provide sufficient driving force to reduce the metal ion to metal. Therefore, we considered using $\mathrm{EY}^{-}$as the reducing agent for in-situ preparation of the alloy catalyst. Due to the excellent performance of the Co-P catalysts in hydrogen generation reactions [23-25], we decided to use Co-based catalysts for visible light hydrogen generation in this study. It has been reported that doping with a small amount of transition metals such as Mo can promote the activity of the Co-B catalyst [26-30]. Patel et al. have reported that the optimum contents of Cr, Mo and $\mathrm{W}$ promoters are $: \chi_{\mathrm{Cr}}=4 \%, \chi_{\mathrm{Mo}}=5 \%$, and $\chi_{\mathrm{W}}=5 \%$, respectively [31]. They believed that the promoting effect of the dopant was mainly due to the increased surface area and the absorbing hydroxyl ions $\left(\mathrm{OH}^{-}\right)$. Cr-doped layered lead niobate 
has been prepared and demonstrated to have superior photocatalytic performance [32]. The key factors for this effect were found to be a narrower band gap and higher separation efficiency of photo induced carriers in the bulk. However, to date, there have been no reports of Co-Mo-P alloy showing high catalytic activity for photocatalytic $\mathrm{H}_{2}$ generation. Thus, we evaluate whether the addition of Mo to the Co-P catalyst would improve its photocatalytic performance.

Due to the excellent electronic, chemical, and mechanical properties as well as large specific surface area of graphene, it is a very attractive supporting substrate for catalyst loading [33-38]. It was found that the increased surface area and the highly conductive surface of graphene could accelerate the generation of hydrogen [39], since the excited electron transfer and separation are limiting factors in the photocatalytic conversion process. Reshak et al. studied the different conformations of graphene and calculated the values of energy gap and the bond lengths[40,41] Modifications of graphene such as the doping with $\mathrm{Cr}$ and $\mathrm{C} / \mathrm{N}$-adsorption can influence the electronic properties and band gap of graphene[42,43]. These studies can help to expand potential future applications of graphene. Previously, We found charge separation and transfer over graphene or g- $\mathrm{C}_{3} \mathrm{~N}_{4}$ could be remarkable enhanced and the catalysts exhibited higher activity for hydrogen generation [44-47].

In this present work, we synthesized and characterized an amorphous Co-Mo-P alloy supported on graphene, and evaluated its application as an efficient hydrogen generation photocatalyst sensitized by EY under visible light irradiation was investigated. Triethanolamine (TEOA) was used as the complexing agent and electron sacrificial agent.

\section{Experimental}

\subsection{Synthesis procedures of graphite oxide (GO) and graphene(GP)}

All materials were of analytical grade and used without further purification. Natural graphite was used to prepare graphite oxide by a modified Hummers method [48, 49]. Firstly, graphite and $\mathrm{NaNO}_{3}$ were added to concentrated $\mathrm{H}_{2} \mathrm{SO}_{4}$, and then $\mathrm{KMnO}_{4}$ was added gradually. The mixture was cooled to $35^{\circ} \mathrm{C}$ and stirred for 2 h. Finally, 3 
deionized water was added to the mixture slowly. The graphite oxide was filtered and washed to remove the sulfate ion, and then the product was dried in a vacuum oven. The graphene was synthesized by reducing the as-prepared graphite oxide using hydrazine hydrate $\left(\mathrm{N}_{2} \mathrm{H}_{4} \cdot \mathrm{H}_{2} \mathrm{O}\right)$ as the reductant [50].In a typical experiment, $80 \mathrm{mg}$ of GO powder was dispersed into $200 \mathrm{~mL}$ of distilled water by ultrasound treatment for 6h. Then, $85 \mu \mathrm{L}$ (85\%) of $\mathrm{N}_{2} \mathrm{H}_{4} \cdot \mathrm{H}_{2} \mathrm{O}$ was added to the aqueous dispersion with the temperature maintained at $95{ }^{\circ} \mathrm{C}$ and the $\mathrm{pH}$ at 10 . After continuous stirring for $10 \mathrm{~h}$, the resulting dark black solution was used as the GP solution with concentration of $0.4 \mathrm{mg} / \mathrm{mL}$.

\subsection{Catalyst preparation and hydrogen generation measurement}

To synthesize the catalysts, $15 \mathrm{~mL}$ of GP $(0.4 \mathrm{mg} / \mathrm{L})$ was dispersed into $80 \mathrm{~mL}$ of TEOA- $\mathrm{H}_{2} \mathrm{O}$ solution $(10 \%, \mathrm{v} / \mathrm{v}, \mathrm{pH}=11)$, followed by ultrasonic treatment for about 15 min to ensure uniform dispersion. Then, $2 \mathrm{~mL}$ of the prepared Co-Mo-P solution was added. The components of the prepared solution are summarized in detail in Table 1. After 15 min of ultrasound treatment the EY (56mg) was added, and the solution was again ultrasonicated for about $15 \mathrm{~min}$. Before irradiation the solution was degassed by bubbling Ar gas through it for 30 min. A 300-W Xenon lamp with a 420 nm cutoff filter was used as the light source.

Gas chromatography (GC-6820, Agilent, USA, Ar carrier) was used to measure the amount of generated hydrogen. The samples were irradiated with light passed through a bandpass filter $(430,460,480,500,520$ or $540 \mathrm{~nm})$ to measure the apparent quantum efficiency (AQE) under the visible light irradiation. Photon flux of the incident light was determined using a Ray virtual radiation actinometer (FU 100)[51]. The prepared solutions were irradiated for 60 min with bandpass filters and the amount of generated hydrogen was measured for AQE tests on the $\mathrm{H}_{2}$ production. The following equation was used to calculate the AQE [48].

$\mathrm{AQE}=2 \times$ (the number of evolved hydrogen molecules/the number of incident photons) $\times 100 \%$ 


\subsection{Catalyst characterization}

The powder X-ray diffraction (XRD, Rigaku D/max-2400) was used to characterize the synthesized catalysts, with $\mathrm{Cu} \mathrm{K} \alpha$ radiation $(\lambda=1.5418 \AA)$ and operated at $40 \mathrm{~mA}$ and $40 \mathrm{kV}$. And the Transmission electron microscopy (TEM, Tecnai-G2-F30) was used to characterize the morphology and the distribution of C, Co, Mo and P elements in the catalysts. The electronic states of Co, Mo and P on the surface of the Co-Mo-P catalyst were analyzed by X-ray photoelectron spectroscopy (XPS, PHI-5702).

\section{Results and discussion}

Fig. 1 shows the XRD patterns of the prepared Co-P/GP and Co-Mo-P/GP catalysts when the $\chi_{\text {Mo }}$ was $10 \%$ and the insert is a detailed analysis of Co-Mo-P/GP catalysts. The peak at about $21^{\circ}$ is attributed to the graphene, and it is lower than the typical diffraction peak of graphene $\left(23.8^{\circ}\right)$ due to the influence of Co-Mo-P nanoparticles loaded on the graphene sheets [52] as well as the incomplete reduction of the GO precursor. The XRD pattern showed a broadpeak at $45^{\circ}$, which is attributed to the amorphous state of the Co-Mo-P alloy. Moreover, the diffraction peaks at around $36^{\circ}$ belonged to the (211) plane of spinel $\mathrm{Co}_{3} \mathrm{O}_{4}$ (JCPDS\#42-1467) [53], while the peak at $59.8^{\circ}$ was attributed to the (031) plane of monoclinic $\mathrm{MoO}_{2}(\mathrm{JCPDS} \# 89-4308)$.

According to Zhuang et al., molybdate is difficult to reduce in aqueous solutions [54], but it gets easily reduced in ethylene glycol in the presence of Co. Thus, the triethanolamine acts as both a complexing agent and a stabilizer, leading to a more thorough reduction of molybdate during the reaction. The amorphous structure exhibits the unique feature of long-range disorder and short-range ordered atomic arrangement. The unsaturated surface coordination sites and crystal defects in the structure can potentially increase the catalytic activity [55].

Fig. 2(a) shows the TEM images of Co-Mo-P/GP catalysts, and it can be seen that the catalyst particles were loaded onto the surface of graphene sheets. Fig. 2(b) shows the high resolution transmission electron microscopy (HRTEM) images of Co-Mo-P/GP catalysts. The crystalline nanoparticles with lattice spacing of $0.28 \mathrm{~nm}$ belonged to (101) planes and $0.34 \mathrm{~nm}$ belonged to (111) planes of monoclinic $\mathrm{MoO}_{2}$. It was observed that the crystalline $\mathrm{MoO}_{2}$ nanoparticles were formed in Co-Mo-P/GP 
nanohybrid. Also, the diameter of Co-Mo-P particles implanted on graphene were about 4-5 nm. Fig. 2(c) clearly shows that the elements of Co, Mo, C and P were distributed in a relatively homogeneous manner on the catalyst surface.

To understand the effect of Mo doping, it is necessary to first study electronic interactions on the surface of the catalyst without Mo. Thus, Fig.3 shows the XPS spectra of Co 2p $\mathrm{p}_{3 / 2}$, Mo 3d and P 2p in the Co-P/GP and Co-Mo-P/GP catalysts. The binding energies of Co 2 $\mathrm{p}_{3 / 2}$ in the Co-P/GP (779eV) and Co-Mo-P/GP (778.8eV) catalysts indicated that the Co metal exists mostly in the elemental state as shown in Fig. 3(a). When comparing the binding energy of pure cobalt(778.1eV) a positive shift is observed. This shift indicates that a part of the Co atom was oxidized, and this oxidation was lower in the Mo doped Co-Mo-P/GP catalyst.

Fig.3 (b) and (c) shows the XPS spectra of Mo 3d and P 2p in the catalyst. The intensity of the peaks was very weak due to the small amounts of Mo and P present. The peaks at $224.2 \mathrm{eV}$ indicated that $\mathrm{Mo} 3 \mathrm{~d}_{5 / 2}$ existed in the elemental form and the peak at $230.1 \mathrm{eV}$ indicated that $\mathrm{Mo} 3 \mathrm{~d}_{5 / 2}$ was present in the form of $\mathrm{MoO}_{2}$ in the Co-Mo-P/GP catalyst [39]. The peak at $237.2 \mathrm{eV}$ was attributed to the interaction of Mo with Co and P. In Fig.3 (c) the peak at $130.7 \mathrm{eV}$ corresponded to the interaction between $\mathrm{P}$ and $\mathrm{Co}$ in Co-P/GP catalyst, while the peak at $131.2 \mathrm{eV}$ was assigned to the interaction of $\mathrm{P}$ with Co and Mo in Co-Mo-P/GP catalyst.

Fig. 4(a) shows the kinetic curves of $\mathrm{H}_{2}$ evolution catalyzed by Co-Mo-P/GP catalyst in $80 \mathrm{~mL}$ of TEOA- $\mathrm{H}_{2} \mathrm{O} 10 \%(\mathrm{v} / \mathrm{v})$ under visible light irradiation $(\lambda \geq 420 \mathrm{~nm})$ at $\mathrm{pH}$ 11. The catalytic activity of the Mo-P catalyst was much lower than that of the other catalysts, indicating the low catalytic activity of Mo in this catalytic system. However, when Mo was added to the Co-P catalysts, the catalytic activity was largely improved. As shown in Fig.4 (a), a series of Co-Mo-P/GP catalysts with different Mo contents were synthesized and used for the photocatalytic $\mathrm{H}_{2}$ generation. The optimal Mo content was found to be $10 \%$. Fig. 4(b) shows the rate of the $\mathrm{H}_{2}$ evolution in $2 \mathrm{~h}$. The maximum hydrogen generation rate of $33.3 \mathrm{mmol}^{\circ} \mathrm{h}^{-1} \cdot \mathrm{gCo}^{-1}$ was obtained by using the Co-Mo-P/GP (10\%) catalyst. This value is 36\% higher than that of the Co-P/GP $\left(24.5 \mathrm{mmol}^{-1} \cdot \mathrm{gCo}^{-1}\right)$ catalyst. According to Patel et al. [31], the 6 
introduction of Mo can prevent the agglomeration of the catalyst by increasing the atomic diffusion barrier. Moreover, the negative shift of Co $2 \mathrm{p}_{3 / 2}$ can increase the density of electrons on the surface of Co in the Co-Mo-P/GP catalyst. These electrons can act as acidic sites to improve the absorption of the reactant species on the surface [56]. The catalyst supported by graphene exhibited excellent photocatalytic activity for hydrogen generation mainly due to the improvement of the charge separation efficiency and extending the lifetime of charge carriers, which increased the density of electrons on the catalyst surface [57].

Since the generation of hydrogen can be strongly affected by the supporting material during photocatalytic $\mathrm{H}_{2}$ evolution, the influence of volume of the added Co-Mo-P(10\%) catalyst solution on the catalytic activity was investigated. As shown in Fig.5, the hydrogen generation volume increased with higher volume of Co-Mo-P(10\%) catalyst solution and reached a maximum at $2 \mathrm{~mL}$. Further increase in volume of the catalyst solution resulted in decreased hydrogen production, which was likely due to agglomeration of the large number of Co-Mo-P catalysts particles on the graphene. The optimal volume of Co-Mo-P(10\%) catalyst solution was found to be $2 \mathrm{~mL}$, which was then used for the subsequent photocatalytic $\mathrm{H}_{2}$ evolution experiments.

Fig.6 shows the AQEs of Co-P/GP and Co-Mo-P/GP catalysts under visible light irradiation at different wavelengths (430, 460, 480, 500, 520 and $540 \mathrm{~nm}$ ). The highest AQE of 52.6\% was reached at $430 \mathrm{~nm}$ in the Co-Mo-P/GP catalyst, which was 6 times higher than the AOE of the un-doped Co-P/GP catalyst.

As shown in Fig.7, the stability of the Co-Mo-P/GP catalyst was tested in $\mathrm{H}_{2}$ generation reaction, photosensitized by EY in TEOA- $\mathrm{H}_{2} \mathrm{O}$ solution $(10 \%, \mathrm{v} / \mathrm{v}, \mathrm{pH}=11)$ under visible light irradiation ( $\lambda \geq 420 \mathrm{~nm}$ ) for $2 \mathrm{~h}$. After completing each experiment, the catalyst was separated using centrifugation and fresh TEOA- $\mathrm{H}_{2} \mathrm{O}$ and EY were added. After the initial few cycles, the $\mathrm{H}_{2}$ evolution drastically decreased by $20 \%$ from $666 \mathrm{~mL}$ to $527 \mathrm{~mL}$ in 2 hours. This was probably due to some amount of the Co-Mo-P catalysts being lost in the process of centrifugation. The $\mathrm{H}_{2}$ evolution activity of the Co-Mo-P catalysts could be maintained after 4 cycles. Thus, the Co-Mo-P catalyst was relatively stable during the photocatalytic $\mathrm{H}_{2}$ evolution 
processes.

\section{Conclusions}

In summary, the Co-Mo-P/GP catalyst was synthesized by a facile in-situ photoelectron reduced deposition for application in the photocatalytic $\mathrm{H}_{2}$ evolution reaction. The Co-Mo-P/GP catalyst showed higher hydrogen generation efficiency when compared with Co-P/GP catalyst. The maximum $\mathrm{H}_{2}$ generation rate was found to be as high as $33.3 \mathrm{mmol} \cdot \mathrm{h}^{-1} \cdot \mathrm{gCo}^{-1}$ when the $\chi_{\text {Mo }}$ was $10 \%$, which was $36 \%$ higher than that of the Co-P/GP $\left(24.5 \mathrm{mmol} \cdot \mathrm{h}^{-1} \cdot \mathrm{gCo}^{-1}\right)$ catalyst. XPS analysis showed that the Co 2p3/2 peak was negatively shifted, which can increase the density of electrons on the surface of Co in the Co-Mo-P/GP catalyst, in turn leading to increased catalytic activity. The highest AQE of $52.6 \%$ was reached at $430 \mathrm{~nm}$ with the Co-Mo-P/GP catalyst, which was 6 times higher than the AQE of the un-doped Co-P/GP catalyst. Moreover, the Co-Mo-P/GP catalyst showed favorable recyclability. Thus, this new Co-Mo-P/GP material is a promising and inexpensive catalyst that can be used for photocatalytic $\mathrm{H}_{2}$ generation in commercial applications.

\section{Acknowledgement:}

This work is supported by the NSF of China (grant no. 21173242 and 21433007), respectively.

\section{References:}

[1] Meng FK, Li JT, Scott KC, Zhi MJ, Wu NQ. Solar Hydrogen Generation by Nanoscale $\mathrm{p}-\mathrm{n}$ Junction of $\mathrm{p}$-type Molybdenum Disulfide/n-type Nitrogen-Doped Reduced Graphene Oxide. J Am Chem Soc 2013;135:10286-10289.

[2] Pan B, Wang Y, Liang YY, Luo SJ, Su WY, Wang XX. Nanocomposite of $\mathrm{BiPO}_{4}$ and reduced graphene oxide as an efficient photocatalyst for hydrogen evolution. Int $\mathrm{J}$ Hydrogen Energy 2014; 39:13527-13533.

[3] Husin H, Su WN, Pan CJ, Liu JY, Rick J, Yang SC, et al. Pd/NiO core/shell nanoparticles on $\mathrm{La}_{0.02} \mathrm{Na}_{0.98} \mathrm{TaO}_{3}$ catalyst for hydrogen evolution from water and 8 
aqueous methanol solution. Int J Hydrogen Energy 2013; 38:1352913540.

[4]Yang Y, Xia LF, Fan ZY, et al. Preparation of nano copper with high dispersion and its effects on photocatalytic hydrogen production on $\mathrm{Cu} / \mathrm{TiO}_{2}$. J Mol Catal (China) 2014; 28(2):182-187.

[5] Li CL, Lei ZQ, Wang QZ, et al. Synthesis of $\mathrm{TiO}_{2}(\mathrm{~B})$ nanobelts photocatalyst for water splitting to $\mathrm{H}_{2}$. J Mol Catal (China) 2015; 29(4): 382-389.

[6] Wu CH, Fang YF, Zhao P, et al. Preparation of Ag-BiVO4 composite and its photocatalytic oxidation mechanism. J Mol Catal (China) 2015; 29(4): 369-381.

[7]Li Z, Wang QS, Kong C, Wu YQ, Li YX, Lu GX. Interface charge transfer vs surface proton reduction, which is more pronounced on photo-induced hydrogen generation over sensitized Pt cocatalyst on RGO?. J Phys Chem C 2015;119(24):13561-13568.

[8] Cui E, Lu G. New evidence for the regulation of photogenerated electron transfer on surface potential energy controlled co-catalyst on $\mathrm{TiO}_{2}$-The investigation of hydrogen production over selectively exposed $\mathrm{Au}$ facet on $\mathrm{Au} / \mathrm{TiO}_{2}$. Int $\mathrm{J}$ Hydrogen Energy 2014; 39:7672-7685.

[9] Dong QS, Yu HC, Jiao ZB, Lu GX, Bi YP. New facile synthesis of one-dimensional Ag@ $\mathrm{TiO}_{2}$ anatase core-shell nanowires for enhanced photocatalytic properties. RSC Adv 2014; 4: 59114-59117.

[10]Peng SQ, Ding M, Yi T, Li YX. Photocatalytic hydrogen evolution in the presence of pollutant methylamines over $\mathrm{Pt} / \mathrm{ZnIn}_{2} \mathrm{~S}_{4}$ under visible light irradiation. J Mol Catal (China) 2014; 28(5): 466-473.

[11]Matthew W, Kanan, YS, Nocera DG. Cobalt-phosphate oxygen-evolving compound. Chem Soc Rev 2009; 38:109-114.

[12] Kanan MW, Nocera DG. In Situ Formation of an Oxygen-Evolving Catalyst in Neutral Water Containing Phosphate and $\mathrm{Co}^{2+}$. Science 2008;321:1072-1075.

[13] Yogesh S, Matthew WK, Daniel GN. Mechanistic Studies of the Oxygen Evolution Reaction by a Cobalt-Phosphate Catalyst at Neutral pH. J Am Chem Soc 2010;132:16501-16509.

[14] Wu YQ, Lu GX, Li SB. Study of preparation and photocatalytic activity of 9 
nanosized $\mathrm{WO}_{3}$ powder. ACTA CHIMICA SINICA 2004; 62(12): 1134-1138.

[15] Ma L, Kang XX, Hu SZ, Wang F. Preparation of Fe, P co-doped graphitic carbon itride with enhanced visible-light photocatalytic activity. J Mol Catal (China) 2015; 29(4): 359-368.

[16] Yu XB, Li HX, Deng JF. Selective hydrogenation of adiponitrile over a skeletal Ni-P amorphous catalyst (Raney Ni-P) at 1 atm pressure. Appl Catal A: Gen 2000; 199:191-198.

[17] Eom KS, Cho KW, Kwon H.S. Effects of electroless deposition conditions on microstructures of cobalt-phosphorous catalysts and their hydrogen generation properties in alkaline sodium borohydride solution. J Power Sources 2008; 180: 484-491.

[18] Li Z, Wu YQ, Lu GX. Highly efficient hydrogen evolution over $\mathrm{Co}(\mathrm{OH})_{2}$ nanoparticles modified g-C3N4 co-sensitized by Eosin Y and Rose Bengal under Visible Light Irradiation. Appl Catal B: Environ 2016; 188: 56-64.

[19] Fernandes R, Patel N, Miotello A. Efficient catalytic properties of Co-Ni-P-B catalyst powders for hydrogen generation by hydrolysis of alkaline solution of $\mathrm{NaBH}_{4}$. Int J Hydrogen Energy 2009;34: 2893-2900.

[20] Guo H, Liu X, Hou Y. Magnetically separable and recyclable urchin-like Co-P hollow nanocomposites for catalytic hydrogen generation. J Power Sources 2014; 260:100-108.

[21] Oh T, Kwon S. Performance evaluation of hydrogen generation system with electroless- deposited Co-P/Ni foam catalyst for $\mathrm{NaBH}_{4}$ hydrolysis. Int J Hydrogen Energy 2013; 38:6425-6435.

[22] Hari DP, König B. Synthetic applications of eosin Y in photoredox catalysis. Chem Commun 2014; 50: 6688-6699.

[23] Cho KW, Kwon HS. Effects of electrodeposited Co and Co-P catalysts on the hydrogen generation properties from hydrolysis of alkaline sodium borohydride solution. Catalysis Today 2007; 120: 298-304

[24] Zhang XW , Zhao JZ, Cheng FY, Liang J, Tao ZL, Chen J. Electroless-deposited $\mathrm{Co}-\mathrm{P}$ catalysts for hydrogen generation from alkaline $\mathrm{NaBH}_{4}$ solution. Int $\mathrm{J}$ Hydrogen 
Energy 2010; 35:8363-8369.

[25] Wu YQ, Lu GX, Li SB. The long-term photocatalytic stability of Co2+-modified P25-TiO2 powders for the $\mathrm{H}-2$ production from aqueous ethanol solution. $\mathrm{J}$

Photochem Photobiol A: Chem 2006; 181(2-3): 263-267.

[26] Ke DD, Tao Y, Li Y, Zhao X, Zhang L, Wang JD, et al. Kinetics study on hydrolytic dehydrogenation of alkaline sodium borohydride catalyzed by

Mo-modified Co-B nanoparticles. Int J Hydrogen Energy 2015; 40:7308-7317.

[27] Wu YQ, Lu GX, Li SB. The Role of Cu(I) Species for Photocatalytic Hydrogen Generation Over $\mathrm{CuOx} / \mathrm{TiO}_{2}$. Catal Lett 2009; 133(1-2): 97-105.

[28] Li Z, Kong C, Lu GX. Visible Photocatalytic Water Splitting and Photocatalytic Two-Electron Oxygen Formation over $\mathrm{Cu}$ - and Fe-Doped g- $\mathrm{C}_{3} \mathrm{~N}_{4}$. J Phys Chem $\mathrm{C}$ 2016; 120(1): 56-63.

[29] Zhang WY, Kong C, Gao W, Lu GX. Intrinsic magnetic characteristics-dependent charge transfer and visible photo-catalytic H-2 evolution reaction (HER) properties of a $\mathrm{Fe}_{3} \mathrm{O}_{4} @ P P y @ P t$ catalyst. Chem Commun 2016; 52(14): 3038-3041.

[30] Kong C, Li Z, Lu GX. Noble-metal-free NiSnxOy decorated graphene cocatalyst for highly efficient reduction of water to hydrogen. Int J Hydrogen Energy 2015; 40(31): 9634-9641.

[31] Patel N, Fernandes R, Miotello A. Promoting effect of transition metal-doped Co-B alloy catalysts for hydrogen production by hydrolysis of alkaline $\mathrm{NaBH}_{4}$ solution. J Catal 2010; 271: 315-324.

[32] Hu YC, Shi JW, Guo LJ. Enhanced photocatalytic hydrogen production activity of chromium doped lead niobate under visible-light irradiation. App Catal A-Gen 2013; 468: 403-409.

[33] Kong C, Min SX, Lu GX. Dye-Sensitized NiSx Catalyst Decorated on Graphene for Highly Efficient Reduction of Water to Hydrogen under Visible Light Irradiation. ACS Catal 2014; 4(8): 2763-2769.

[34] Kong C, Min SX, Lu GX. A novel amorphous CoSnxOy decorated graphene nanohybrid photocatalyst for highly efficient photocatalytic hydrogen evolution. Chem Commun 2014; 50(39): 5037-5039. 
[35] Min SX, Lu GX. Promoted photoinduced charge separation and directional electron transfer over dispersible xanthene dyes sensitized graphene sheets for efficient solar H-2 evolution. Int J Hydrogen Energy 2013; 38(5): 2106-2116.

[36] Dikin DA, Stankovich S, Zimney EJ, Piner RD, Dommett GHB, Evmenenko G, et al. Preparation and characterization of graphene oxide paper. Nature 2007; 448: 457-460.

[37] Xiang Q, Yu J. Graphene-based photocatalysts for hydrogen generation. J Phys Chem Lett 2013; 4:753-759.

[38] Zhou W, Hu XL, Zhao XR et al. Preparation of graphene-BiBr composite and the enhanced photocatalytic activity under visible-light irradiation. J Mol Catal (China) 2014; 28(4): 367-375.

[39] Saha S, Basak V, Dasgupta A, Ganguly B, Banerjee D, Kargupta K. Graphene supported bimetallic G-Co-Pt nanohybrid catalyst for enhanced and cost effective hydrogen generation. Int J Hydrogen Energy 2014; 39: 11566-11577.

[40] Reshak AH, Auluck S. Electronic and optical properties of chair-like and boat-like graphane. RSC Adv 2014; 4:37411-37418.

[41] Reshak AH. Thermoelectric properties of fully hydrogenated graphene: Semi-classical Boltzmann theory. J Appl Phys 2015; 117: 225104-225107

[42] Thakur J, Kashyap MK, Saini HS, Reshak AH. Half metallicity and magnetism in graphene containing monovacancies decorated with Carbon/Nitrogen adatom. J Alloy Compd 2016; 663:100-106.

[43] Thakur J, Kashyap MK, Saini HS, Reshak AH. Enhanced magnetic response and metallicity in AB stacked bilayer graphene via Cr-doping. J Alloy Compd 2015; 649:1300-1305.

[44] Li Z, Kong C, Lu GX. Rhodium tin composite oxides co-catalyst for high efficient photocatalytic hydrogen evolution. Int J Hydrogen Energy 2015; 40(30): 9061-9068.

[45] Kong C, Li Z, LU GX. The dual functional roles of Ru as co-catalyst and stabilizer of dye for photocatalytic hydrogen evolution. Int J Hydrogen Energy 2015; 40(17): 5824-5830.

[46] Min SX, Lu GX. Enhanced Electron Transfer from the Excited Eosin Y to 
mpg- $\mathrm{C}_{3} \mathrm{~N}_{4}$ for Highly Efficient Hydrogen Evolution under $550 \mathrm{~nm}$ Irradiation. J Phys Chem C 2012; 116(37): 19644-19652.

[47] Min SX, Lu GX. Dye-Sensitized Reduced Graphene Oxide Photocatalysts for Highly Efficient Visible-Light-Driven Water Reduction. J Phys Chem C 2011; 115(28): 13938-13945.

[48] Kong C, Min SX, Lu GX. Dye-sensitized cobalt catalysts for high efficient visible light hydrogen evolution. Int J Hydrogen Energy 2014; 39:4836-4844.

[49] Kovtyukhova NI, Ollivier PJ, Martin BR, Mallouk TE, Chizhik SA, Buzaneva $\mathrm{EV}$, et al. Layer-by-layer assembly of ultrathin composite films from micron-sized graphite oxide sheets and polycations. Chem Mater 1999; 11:771-778.

[50]Min SX, Lu GX. Dye-cosensitized graphene/Pt photocatalyst for high efficient visible light hydrogen evolution. Int J Hydrogen Energy 2012; 37:10564-10574.

[51]Min SX, Lu GX. Sites for High efficient photocatalytic hydrogen evolution on a limited-Layered $\mathrm{MoS}_{2}$ cocatalyst confined on graphene sheets-the role of graphene. J Phys Chem C, 2012;116: 25415-25424.

[52] Shin HJ, Kim KK, Benayad A, Yoon SM, Park HK, et al. Efficient reduction of graphite oxide by sodium borohydride and its effect on electrical conductance. Adv Funct Mater

2009;19:1987-1992.

[53] Wang WL, Zhao YC, Chen DH, Wang X, Peng XG, et al. Promoted Mo incorporated Co-Ru-B catalyst for fast hydrolysis of $\mathrm{NaBH}_{4}$ in alkaline solutions. Int $\mathrm{J}$ Hydrogen Energy 2014; 39: 16202-16211.

[54]Zhang DW, Kang Q, Muir SS, Yao X, Dai HB, et al. Evaluation of a cobalte-molybdenume-boron catalyst for hydrogen generation of alkaline sodium borohydride solution-aluminum powder system. J Power Sources 2013; 224:304-311. [55] Yan P, Zhou GB, Nguyen L, Zong BM, Qiao MH, et al. Synthesis and catalysis of chemically reduced metal-metalloid amorphous alloys. Chem Soc Rev 2012; 4:8140-8162.

[56] Li HX, Wu YD, Zhang J, Dai WL, Qiao MH. Liquid phase acetonitrile hydrogenation to ethylamine over a highly active and selective $\mathrm{Ni}-\mathrm{Co}-\mathrm{B}$ amorphous alloy catalyst. Appl Catal A: Gen 2004; 275:199-206. 
[57] Kong C, Min SX, Lu GX. Robust Pt-Sn alloy decorated graphene nanohybrid cocatalyst for photocatalytic hydrogen evolution. Chem Commun 2014; 50: 9281-9283. 
Table1 (The composition of the prepared catalysts solution)

Fig. 1 (The XRD patterns of the catalysts)

Fig. 2(The morphology the prepared catalysts and the elemental mapping images)

Fig. 3 (XPS survey spectra of Co2p, Mo 3d and P 2p scan spectra of prepared catalysts)

Fig.4 (Kinetic curves and the rate of the $\mathrm{H}_{2}$ evolution of photocatalytic $\mathrm{H}_{2}$ evolution)

Fig.5 (The $\mathrm{H}_{2}$ production comparison of the catalysts with different Co-Mo-P solution volumes)

Fig.6 (The AQEs of $\mathrm{H}_{2}$ evolution for the prepared catalysts)

Fig.7 (The stability testing of the Co-Mo-P/GP catalysts) 


\section{Table1}

Composition of the catalysts solution

\begin{tabular}{cccc}
\hline catalysts & \multicolumn{3}{c}{ Component } \\
\cline { 2 - 4 } & $\mathrm{CoSO}_{4} \cdot 7 \mathrm{H}_{2} \mathrm{O}$ & $\mathrm{Na}_{2} \mathrm{MO}_{4} \cdot 2 \mathrm{H}_{2} \mathrm{O}$ & $\mathrm{NaH}_{2} \mathrm{PO}_{2} \cdot \mathrm{H}_{2} \mathrm{O}$ \\
\hline Co-P & $0.1 \mathrm{~mol} / \mathrm{L}$ & 0 & $0.02 \mathrm{~mol} / \mathrm{L}$ \\
$\mathrm{Co}-\mathrm{Mo}-\mathrm{P}(10 \%)$ & $0.09 \mathrm{~mol} / \mathrm{L}$ & $0.01 \mathrm{~mol} / \mathrm{L}$ & $0.02 \mathrm{~mol} / \mathrm{L}$ \\
$\mathrm{Co}-\mathrm{Mo}-\mathrm{P}(20 \%)$ & $0.08 \mathrm{~mol} / \mathrm{L}$ & $0.02 \mathrm{~mol} / \mathrm{L}$ & $0.02 \mathrm{~mol} / \mathrm{L}$ \\
$\mathrm{Co}-\mathrm{Mo}-\mathrm{P}(50 \%)$ & $0.05 \mathrm{~mol} / \mathrm{L}$ & $0.05 \mathrm{~mol} / \mathrm{L}$ & $0.02 \mathrm{~mol} / \mathrm{L}$ \\
$\mathrm{Mo}-\mathrm{P}$ & 0 & $0.1 \mathrm{~mol} / \mathrm{L}$ & $0.02 \mathrm{~mol} / \mathrm{L}$ \\
\hline
\end{tabular}




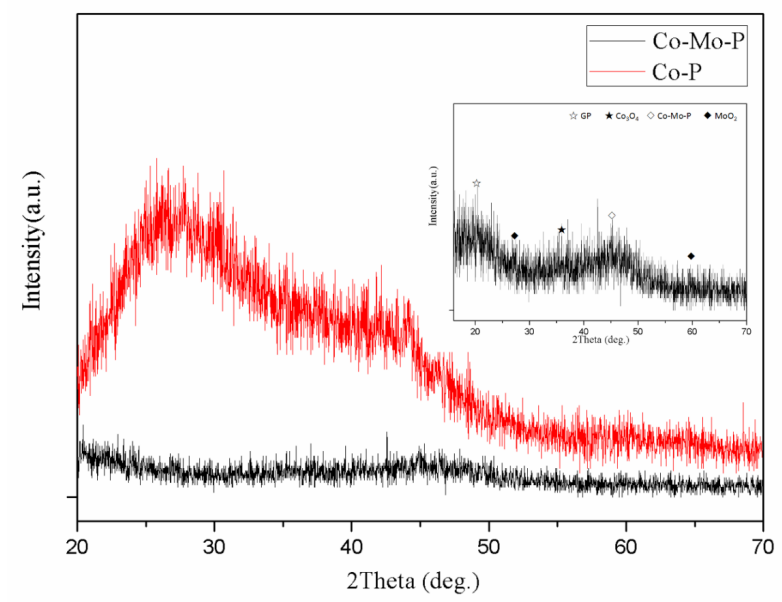

Fig. 1 The XRD patterns of the Co-P/GP and Co-Mo-P/GP (10\%) catalysts. 

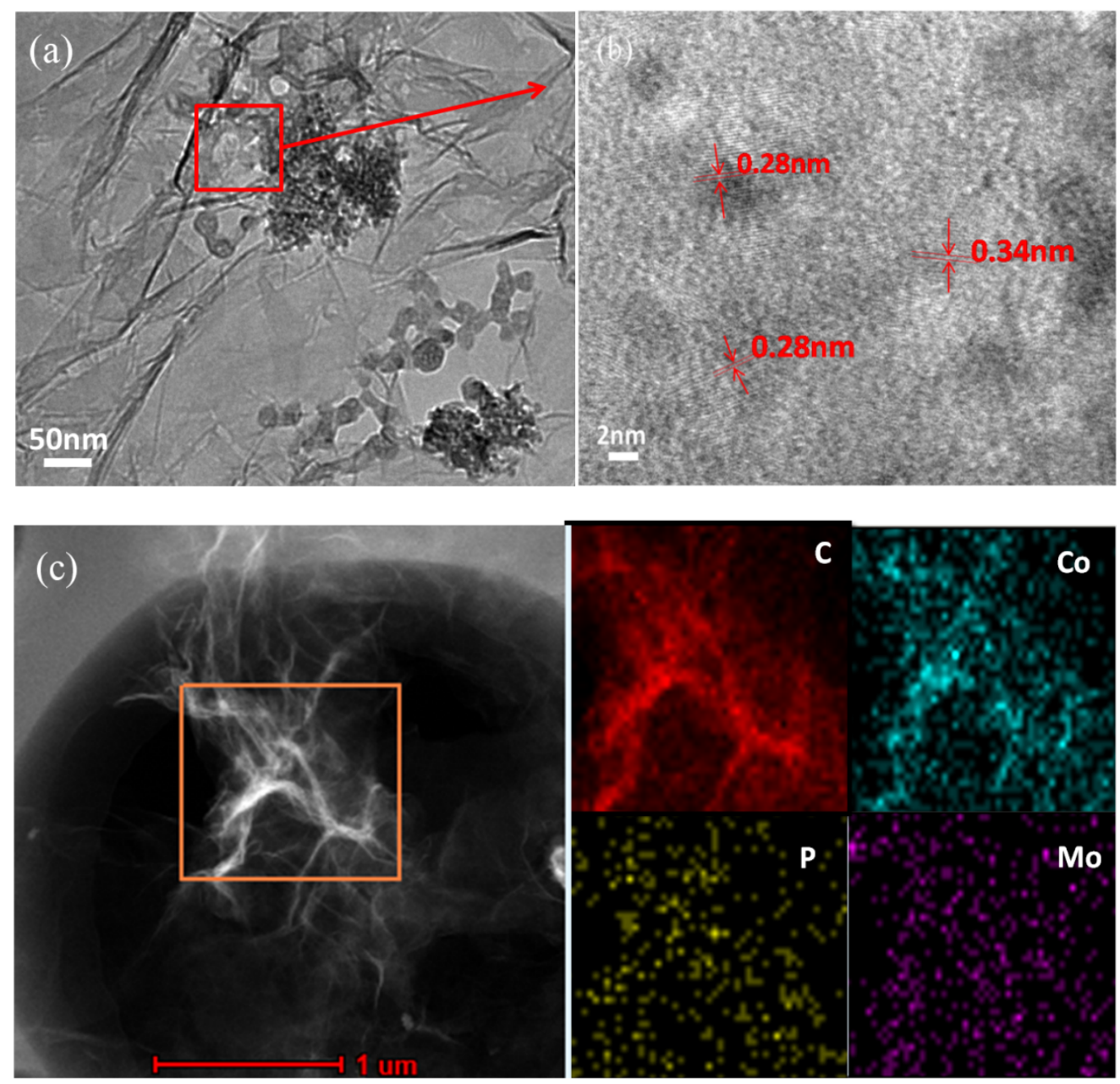

Fig. 2 TEM image (a), HRTEM image (b) and HAADF-STEM (high-angle annular dark field scanning transmission electron microscopy) image and elemental mapping images(c) of Co-Mo-P(10\%) catalysts. 

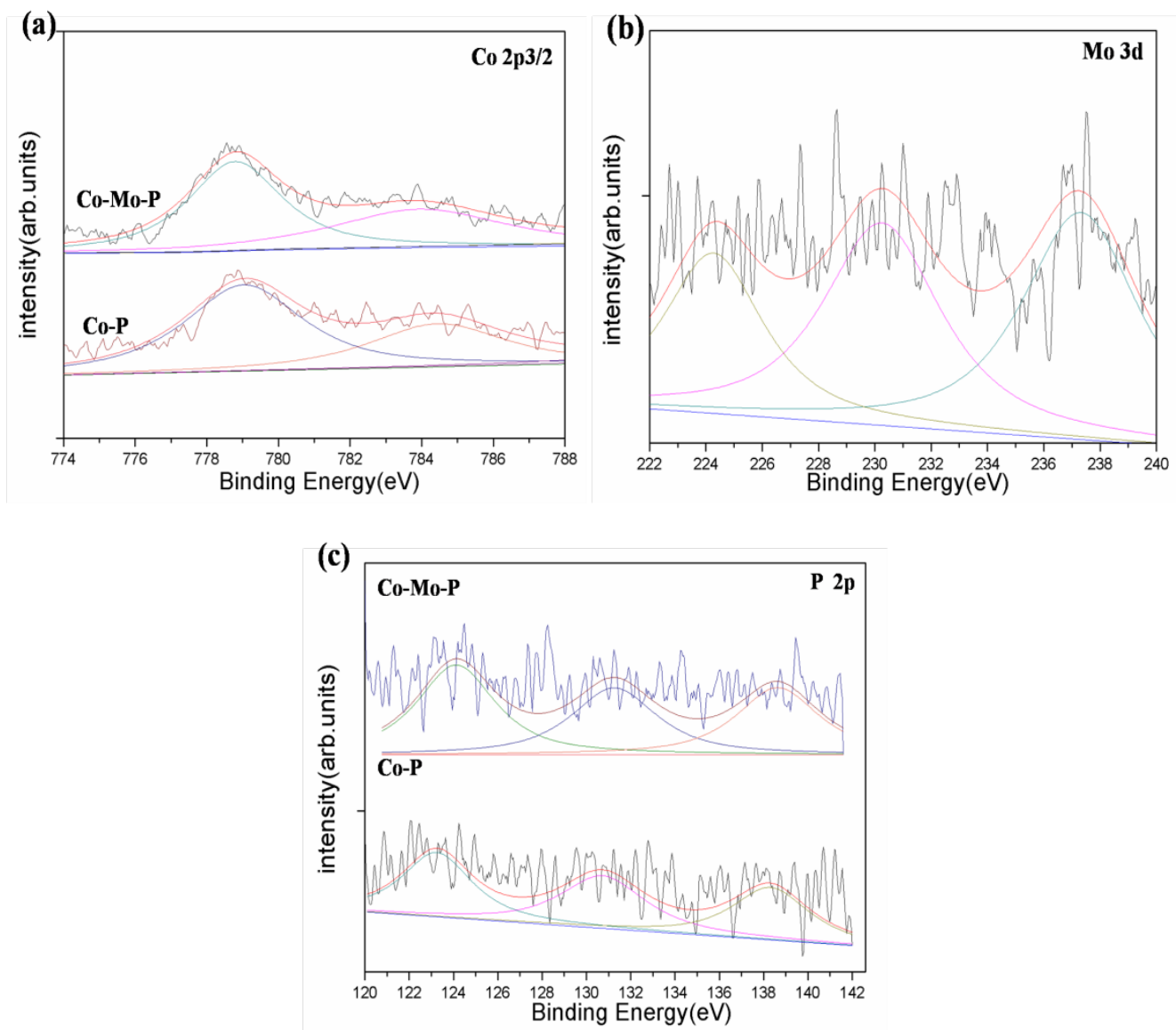

Fig. 3 XPS survey spectra of Co 2 $p_{3 / 2}$ scan spectra(a), Mo 3d scan spectra(b) and P 2p scan spectra(c) of Co-Mo-P/GP(10\%) and Co-P/GP catalysts. 

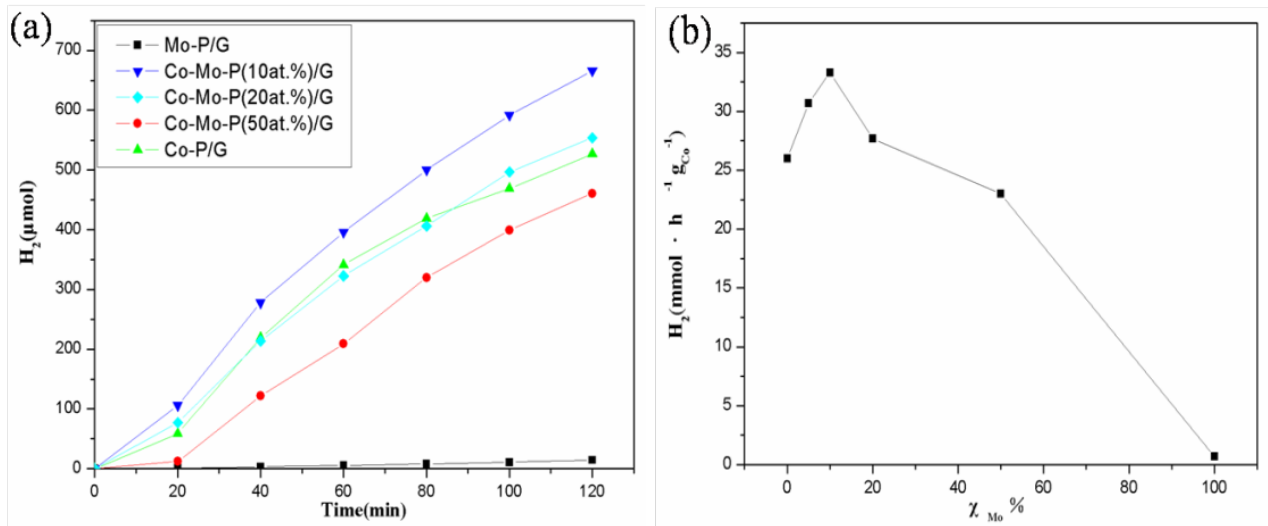

Fig.4 Kinetic curves of photocatalytic $\mathrm{H}_{2}$ evolution from water over the catalysts (a) and the rate of the $\mathrm{H}_{2}$ evolution in $2 \mathrm{~h}(\mathrm{~b})$. 


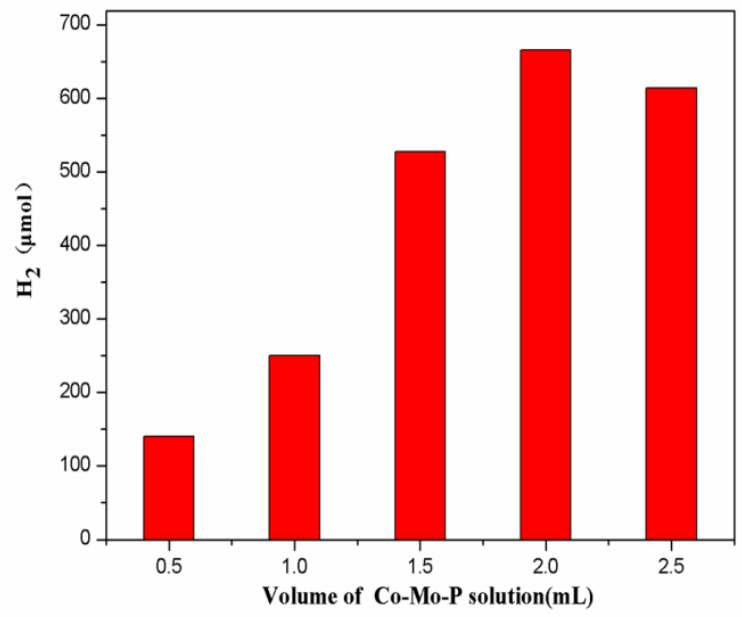

Fig.5 The $\mathrm{H}_{2}$ production comparison of the catalysts with different Co-Mo-P(10\%) solution volumes in $2 \mathrm{~h}$. 


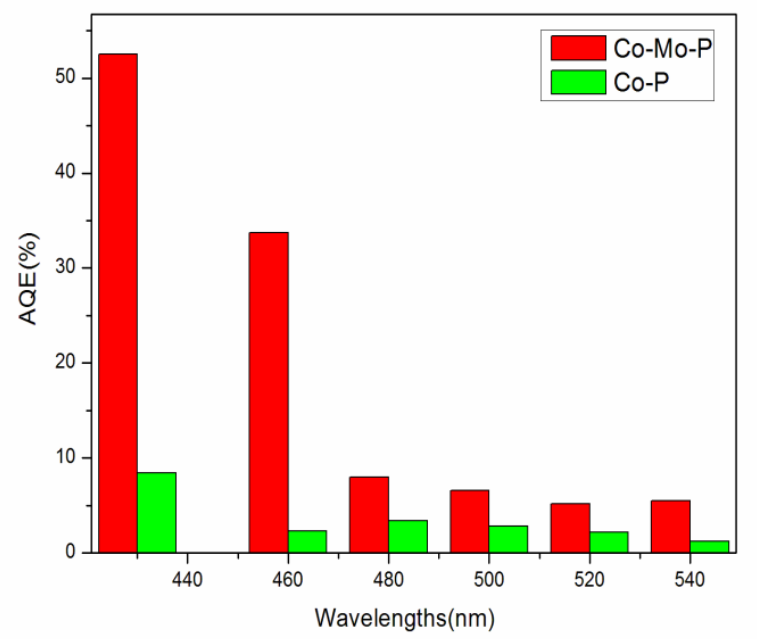

Fig.6 Apparent quantum efficiencies (AQEs) of $\mathrm{H}_{2}$ evolution for Co-P/GP and Co-Mo-P/GP(10\%) catalysts. 


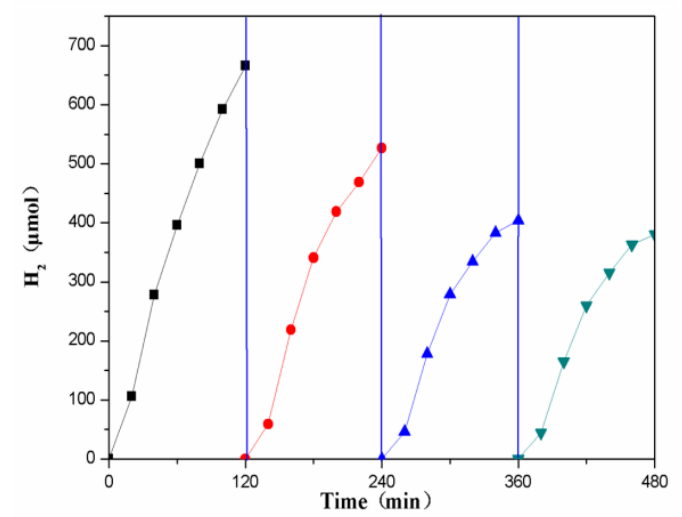

Fig.7 The stability testing and the compare of $\mathrm{H}_{2}$ evolution over the Co-Mo-P/GP(10\%)catalysts. 